\title{
Mechanism of reverse rate-dependent action of cardioactive agents
}

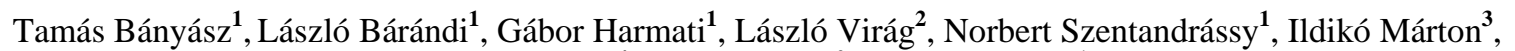
Antonio Zaza ${ }^{4}$, András Varró2 , Péter P. Nánási ${ }^{1}$

${ }^{1}$ Department of Physiology, University of Debrecen, Hungary

${ }^{2}$ Department of Pharmacology and Pharmacotherapy, University of Szeged, Hungary

${ }^{3}$ Department of Dentistry, University of Debrecen, Hungary

${ }^{4}$ Dipartimento di Biotecnologie e Bioscienze, Universita di Milano-Bicocca, Italy

Running title: reverse rate-dependent drug action

\author{
Correspondence: \\ Tamás Bányász, M.D., Ph.D. \\ Department of Physiology, University of Debrecen \\ Nagyerdei krt. 98. H-4012 Debrecen, Hungary \\ Phone: +36-52-255575 \\ FAX: +36-52-255116 \\ E-mail:banyasz@phys.dote.hu
}

\begin{abstract}
Class 3 antiarrhythmic agents exhibit reverse rate-dependent lengthening of the action potential duration (APD), i.e. changes in APD are greater at longer than at shorter cycle lengths. In spite of the several theories developed to explain this reverse rate-dependency, its mechanism has been clarified only recently. The aim of the present study is to elucidate the mechanisms responsible for reverse rate-dependency in mammalian ventricular myocardium. Action potentials were recorded using conventional sharp microelectrodes from human, canine, rabbit, guinea pig, and rat ventricular myocardium in a ratedependent manner. Rate-dependent drug-effects of various origin were studied using agents known to lengthen or shorten action potentials allowing thus to determine the drug-induced changes in APD as a function of the cycle length. Both drug-induced lengthening and shortening of action potentials displayed reverse rate-dependency in human, canine, and guinea pig preparations, but not in rabbit and rat myocardium. Similar results were obtained when repolarization was modified by injection of inward or outward current pulses in isolated canine cardiomyocytes. In contrast to reverse rate-dependence, druginduced changes in APD well correlated with baseline APD values (i.e. that measured before the superfusion of drug or injection of current) in all of the preparations studied. Since the net membrane current $\left(\mathrm{I}_{\mathrm{net}}\right)$, determined from the action potential waveform at the middle of the plateau, was inversely proportional to APD, and consequently to cycle length, it is concluded that that reverse rate-dependency may simply reflect the inverse relationship linking $\mathrm{I}_{\text {net }}$ to APD. In summary, reverse rate-dependency is an intrinsic property of drug action in the hearts of species showing positive APD - cycle length relationship, including humans. This implies that development of a pure $\mathrm{K}^{+}$channel blocking agent without reverse ratedependent effects is not likely to be successful.
\end{abstract}

\section{Keywords}

action potential duration, class 3 antiarrhythmics, mammalian myocardium, membrane current, reverse rate dependence, ventricular repolarization 


\section{INTRODUCTION}

Dofetilide, d-sotalol, E-4031, ibutilide, and many UK compounds, which are selective blockers of the rapid delayed rectifier $\mathrm{K}^{+}$current, are the most prominent representatives of class 3 antiarrhythmic agents. These drugs typically contain a methanesulfonamidophenyl structure within the molecule - in the case of dofetilide in two copies - (Fig. (1)) and display reverse rate-dependent effects. According to this mode of action a drug-induced lengthening of APD is greater at longer than at shorter cycle lengths [1, 2]. The reverse rate-dependent nature of the APD lengthening is undesirable because it minimizes drug effects on repolarization during tachyarrhythmias, while enhances their proarrhythmic potential at normal heart rates $[1,3,4]$. Therefore, development of class 3 drugs having direct rate-dependent properties when lengthening APD (i.e. lengthen APD better at shorter cycle lengths) was believed to be straightforward.<smiles>Cc1cccc(CCN2CCC(C(=O)c3ccc(NS(C)(=O)=O)cc3)CC2)n1</smiles><smiles>CC(C)NC[C@H](O)c1ccc(NS(C)(=O)=O)cc1</smiles><smiles>CCCCCCC[NH2+]CCCC(O)c1ccc(NS(C)(=O)=O)cc1</smiles>

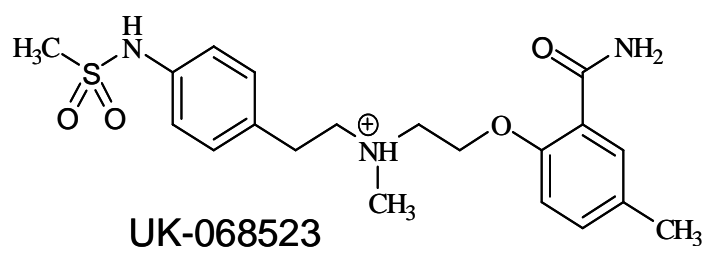<smiles>C[NH+](CCOc1ccc(C(F)(F)F)cc1)CCc1ccc(NS(C)(=O)=O)cc1</smiles><smiles>C[NH+](CCOc1ccc(C(N)=O)cc1)CCc1ccc(NS(C)(=O)=O)cc1</smiles>

Fig. (1) Chemical structures of $\mathrm{I}_{\mathrm{Kr}}$ blocker class 3 antiarrhythmic agents. Note the methanesulfonamidophenyl structure present in each compound (twice in dofetilide).

Several hypotheses have been developed so far to explain the mechanism responsible for the reverse ratedependent APD modulation of class 3 antiarrhythmics. Based on results obtained in guinea pig ventricular myocytes, it was first suggested that significant accumulation of $\mathrm{I}_{\mathrm{Ks}}$ may occur due to the incomplete deactivation of the current at fast heart rates, which would greatly attenuate the APD lengthening effect of $\mathrm{I}_{\mathrm{Kr}}$ blockade [5]. This theory is strongly opposed by the finding that reverse rate-dependency was evident after full suppression of $\mathrm{I}_{\mathrm{Ks}}[\mathbf{6}]$. 
Another hypothesis, the modulated receptor theory, was based on the rate-dependency of drug-channel interaction. Drug access to the channel and its binding and unbinding rates depend on the state of the channel $[7,8]$, which dynamically changes during the cardiac cycle. If the channel block developed preferentially during the diastole and dissipated during the action potential, reverse rate-dependent prolongation of APD would be expected.

According to a third hypothesis the effect of $\mathrm{I}_{\mathrm{Kr}}$ blockers is reduced, and consequently the drug-induced prolongation of APD becomes diminished, at fast heart rates due to the potassium accumulation in the sarcolemmal clefts. This theory was based on observations showing that $\mathrm{I}_{\mathrm{Kr}}$ blockade by quinidine and dofetilide was attenuated when extracellular potassium concentration was elevated [9].

These latter two explanations had to be questioned after recognizing that many drugs that are known to lengthen APD independently of $\mathrm{I}_{\mathrm{Kr}}$ blockade, like the $\mathrm{I}_{\mathrm{to}}$ blocker 4-aminopyridine, the $\mathrm{I}_{\mathrm{Ks}}$ inhibitor chromanol 293B and HMR 1556, the non-specific $\mathrm{K}^{+}$channel blocker tetraethylammonium, the $\mathrm{I}_{\mathrm{Ca}}$ activator BAY K 8644, or the $\mathrm{I}_{\mathrm{Na}}$ activator veratridine, also exert reverse rate-dependent actions on APD. In other words, the phenomenon of reverse rate-dependency is not restricted to $\mathrm{I}_{\mathrm{Kr}}$ blockade, but is observed with several drugs that lengthen APD independently of the underlying ionic mechanism. Due to the diversity of the chemical structures of agents in question (Fig. (2)), the modulated receptor theory is not likely to explain the phenomenon of reverse rate-dependency.<smiles>CN([C@H]1c2cc(OCCCC(F)(F)F)ccc2OC(C)(C)[C@@H]1O)S(C)(=O)=O</smiles>

HMR 1556

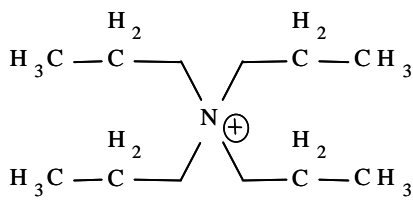

tetraethylammonium<smiles>CCS(=O)(=O)N(C)[C@H]1c2cc(C#N)ccc2OC(C)(C)[C@H]1O</smiles>

chromanol 293B<smiles>COC(=O)C1=C(C)NC(C)=C([N+](=O)[O-])[C@H]1c1ccccc1C(F)(F)F</smiles>

BAY-K 8644<smiles>Nc1ccncc1</smiles>

4-aminopyridine

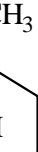

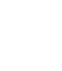


<smiles>CCN(CC)CC(=O)Nc1c(C)cccc1C</smiles>

lidocaine

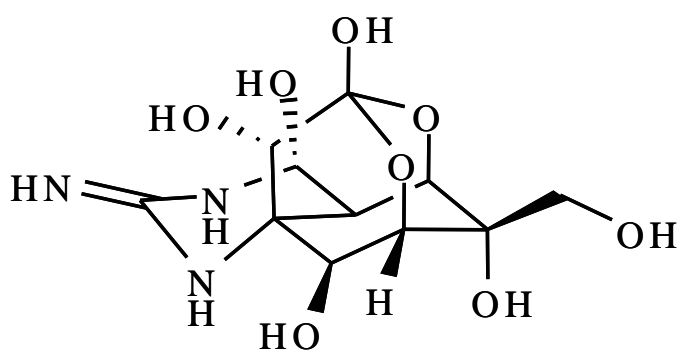

tetrodotoxin<smiles>CC1(C)Oc2ccc(C#N)cc2[C@H](N2CCCC2=O)[C@@H]1O</smiles>

lemakalim<smiles>Cc1cccc(C)c1OCC(C)N</smiles>
mexiletine<smiles>COC(=O)C1=C(C)NC(C)=C(C(=O)OC)C1c1ccccc1[N+](=O)[O-]</smiles>

nifedipine<smiles>O=C(NCCC[N+](=O)[O-])c1cccnc1</smiles>

Fig. (3) Chemical structures of drugs known to shorten APD either by blocking $\mathrm{I}_{\mathrm{Na}}$ (lidocaine, mexiletine, tetrodotoxin) and $\mathrm{I}_{\mathrm{Ca}}$ (nifedipine), or by activating the ATP-sensitive $\mathrm{K}^{+}$current (lemakalim and nicorandil).

The multitude of theories developed so far to explain reverse rate-dependency indicates that its exact mechanism remained to be elucidated. In a recent study performed in dog myocardium APD modulation by drugs with diverse mechanisms was invariably characterized by reverse rate-dependency [12]. This was interpreted as reverse rate-dependence being a general intrinsic property of cardiac tissues, independently of the drug, tissue, or species studied, resulting from the shape of the relationship between the net membrane current $\left(\mathrm{I}_{\mathrm{net}}\right)$ and APD $[12,13]$. Such an interpretation was based on the assumption that APD modulation depends on drug-induced changes in $\mathrm{I}_{\mathrm{net}}$, independently of the specific current affected. This interpretation also predicts that, instead of depending on the heart rate (as suggested by the term reverse rate-dependency), the extent of drug-induced APD change may be a function of baseline APD, while the latter being a function of rate. Indeed, comparing reverse rate-dependency in various species it turned out that the magnitude of the drug-induced APD changes better correlated with baseline APD than with cycle length [14, 15].

In the present study we analyze all data regarding the rate-dependent properties of APD modulation by applying a variety of drugs that either enhance or block cardiac ion currents. Properties of ventricular myocardium of several mammalian species, including human, dog, rabbit, guinea pig and rat cardiac tissues are compared. Effects of transmembrane current injections were also studied as they were used to mimic the effects of ion channel blockers and activators in isolated cardiac cells. 


\section{Dog ventricle}

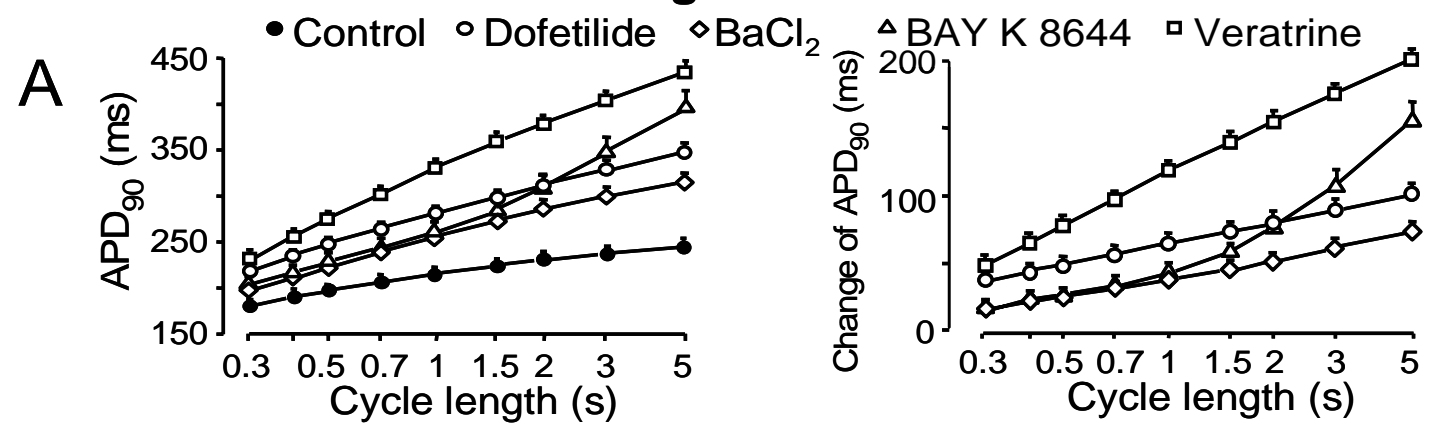

\section{Dog Purkinje}

- Control $\diamond$ Nicorandil ${ }^{\circ}$ Lidocaine
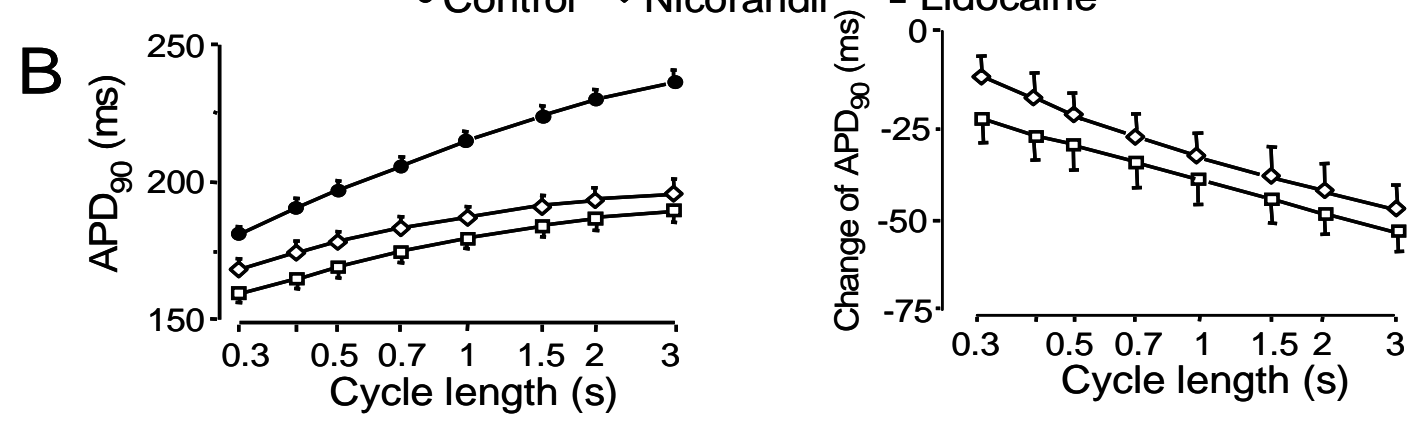

\section{Guinea pig ventricle}

- Control oSotalol ㅁ Lemakalim
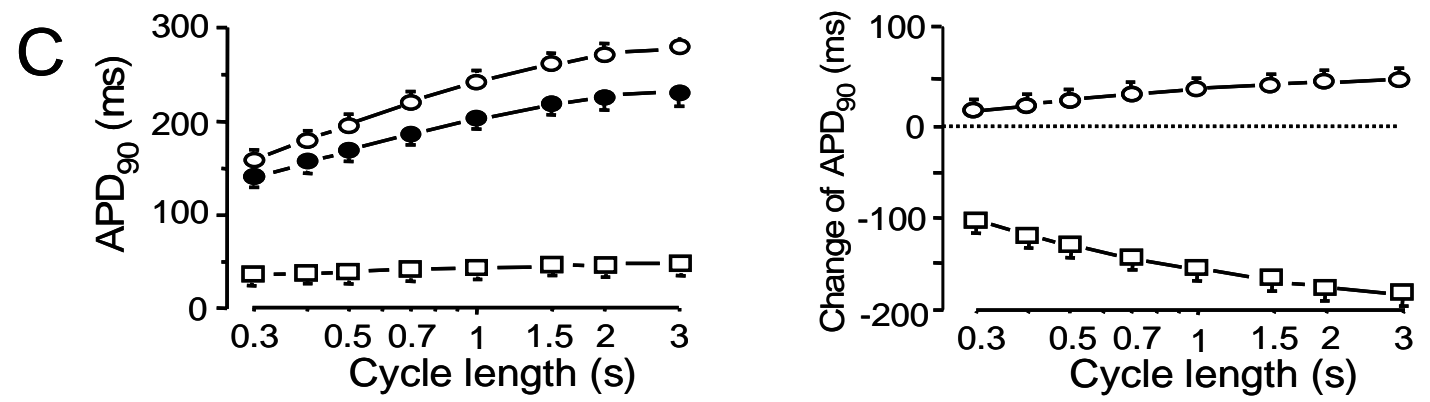

\section{Human ventricle}

- Control $\circ$ Dofetilide $\square$ Sotalol $\diamond \mathrm{E}-4031 \backsim \mathrm{BaCl}_{2} \triangle$ Mexiletine $\nabla T T X$

D

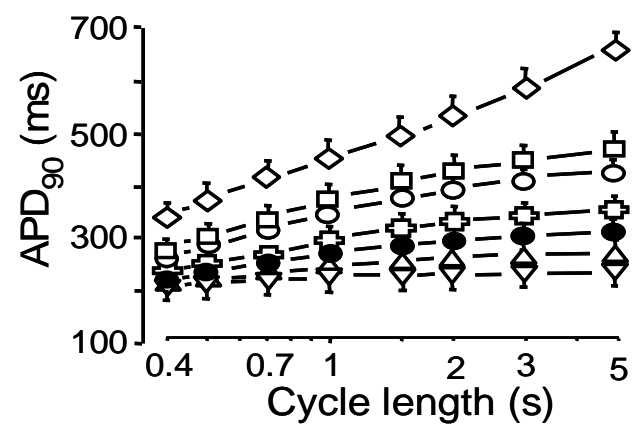

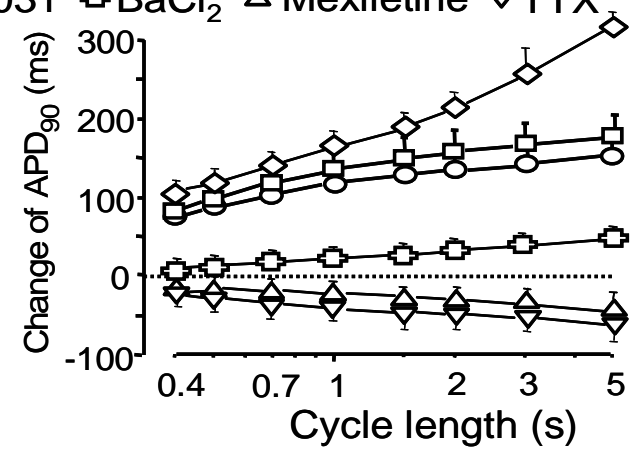

Fig. (4) Reverse rate-dependent actions of agents known to either lengthen ( $1 \mu \mathrm{M}$ dofetilide, $1 \mu \mathrm{M}$ E-4031, $30 \mu \mathrm{M}$ d-sotalol, $10 \mu \mathrm{M} \mathrm{BaCl}_{2}, 1 \mu \mathrm{M}$ BAY K 8644, $1 \mu \mathrm{g} / \mathrm{ml}$ veratrine) or shorten APD (15 $\mu \mathrm{M}$ lemakalim, $100 \mu \mathrm{M}$ nicorandil, $10 \mu \mathrm{M}$ lidocaine, $10 \mu \mathrm{M}$ mexiletine, $2 \mu \mathrm{M}$ tetrodotoxin). Recordings were taken from multicellular preparations obtained from canine (A, B), guinea pig (C), and undiseased human (D) hearts using sharp microelectrodes. 


\section{REVERSE RATE-DEPENDENT NATURE OF APD MODIFICATION IN MAMMALIAN MYOCARDIUM}

Since the canine ventricular myocardium resembles most the human one regarding its electrophysiological properties [16-19], the frequency-dependent effects of various APD lengthening agents are demonstrated in canine multicellular ventricular preparations first.

As shown in Fig. (4.A), the $\mathrm{I}_{\mathrm{Kr}}$ blocker dofetilide [5], $\mathrm{I}_{\mathrm{K} 1}$ blocker $\mathrm{BaCl}_{2}$ [20], the $\mathrm{I}_{\mathrm{Ca}}$ activator $\mathrm{BAY} \mathrm{K} 8644$ [21], and the $\mathrm{I}_{\mathrm{Na}}$ activator veratrine [22], display clearly reverse rate-dependent action on APD, i.e. the lengthening of APD increased monotonically with increasing the cycle length of stimulation, independently of the drug applied or the ion channel activated or blocked. This reversely rate-dependent prolongation of APD was equally observed if the change in APD was expressed in absolute values (in ms) or in a percentage form. These results clearly indicate that the reverse rate-dependent lengthening of APD is not restricted to $\mathrm{I}_{\mathrm{Kr}}$ blockade, but is observed with any drug that is able to lengthen APD.

In another preparation, in free running canine Purkinje strands, drugs known to shorten the cardiac action potentials were tested. Again, two agents having different targets to exert their shortening effects were applied. Lidocaine is known to suppress the window $\mathrm{Na}^{+}$current [23], while nicorandil is a frequently used ATP-sensitive $\mathrm{K}^{+}$channel opener [24]. As presented in Fig. (4.B), the effects of these agents on APD were not only similar in size, but their frequency-dependence was also almost identical: both drugs shortened APD stronger at longer than at shorter cycle lengths. In other words, not only the frequency-dependent lengthening of APD but also its shortening shows the properties of reverse rate-dependence.

Basically similar results were obtained when a variety of APD lengthening and shortening agents were tested in other mammalian cardiac preparations including papillary muscles of the guinea pig and those derived from undiseased human hearts (Figs. (4.C) and (4.D)). All the agents applied to lengthen (the $\mathrm{I}_{\mathrm{Kr}}$ blocker dofetilide, sotalol, and $\mathrm{E}-4031$, the $\mathrm{I}_{\mathrm{K} 1}$ blocker $\mathrm{BaCl}_{2}$ ) or shorten (the $\mathrm{I}_{\mathrm{Na}}$ blocker mexiletin and tetrodotoxin) APD shared the property of reverse rate-dependence. At this point one might conclude that the reverse rate-dependent nature of drug-action in the heart is a general property of mammalian cardiac tissues, independent of the species or preparation used, of the ion channel modified, or the direction of the resultant APD change. In the followings we examine that whether really is that the case?

\section{REVERSE RATE-DEPENDENT MODIFICATION OF APD DEPENDS ON THE LENGTH OF BASELINE APD}

The coincidence observed between human and canine ventricular tissues is not surprising, because the electrophysiological properties of human and canine myocardium are believed to be quite similar [16-19]. In contrast, the type and density of ion channels underlying the action potential in rabbit hearts are markedly different from those found in dog and human [25]. More importantly, APD displays a nonmonotonic dependency on cycle length in rabbits, maximum APD being achieved at an intermediate cycle length between 0.5 and $0.7 \mathrm{~s}$ as it is demonstrated in Fig. (5.A). This provides a unique opportunity to discriminate between rate-dependency and APD-dependency of drug-induced APD changes. In this case, sotalol [26] and lemakalim [27] were used to prolong and shorten APD, respectively. As expected, sotalol lengthened and lemakalim shortened APD in rabbit papillary muscles at all frequencies. However, in contrast to results obtained in canine, human, and guinea pig preparations, where the APD lengthening and shortening displayed monotonic reverse rate-dependency, the maximal drug-induced APD changes in rabbit preparations occurred at the intermediate cycle length between 0.5 and $0.7 \mathrm{~s}$, at which the baseline APD was the longest (Fig. (5.A)). According to this result the magnitude of drug-effect seems to depend on the duration of the baseline action potential, rather than on the pacing rate, suggesting that longer action potentials are more sensitive to modulation than shorter ones, irrespective of the actual pacing rate.

The above hypothesis can be best examined by studying the frequency-dependent properties of actions of various $\mathrm{K}^{+}$and $\mathrm{Ca}^{2+}$ channel inhibitors on APD during the electrical restitution process of rat ventricular muscle. This preparation was chosen because (1) it has a set of ion currents markedly different from those of other species, and consequently, (2) its APD is shorter by one order of magnitude than that of the plateau-forming larger mammals [28-30], and most importantly, (3) its APD increases at higher heart rates - opposite to many other species [31, 32]. Therefore, the APD lengthening effect of the $\mathrm{K}^{+}$channel blocker 4-aminopyridine and tetraethylammonium, as well as the APD shortening effect of the $\mathrm{Ca}^{2+}$ channel blocker nifedipine and $\mathrm{MnCl}_{2}$ [33] was studied in rat as a function of the diastolic interval, a parameter indicating the proximity of the action potentials [34]. 


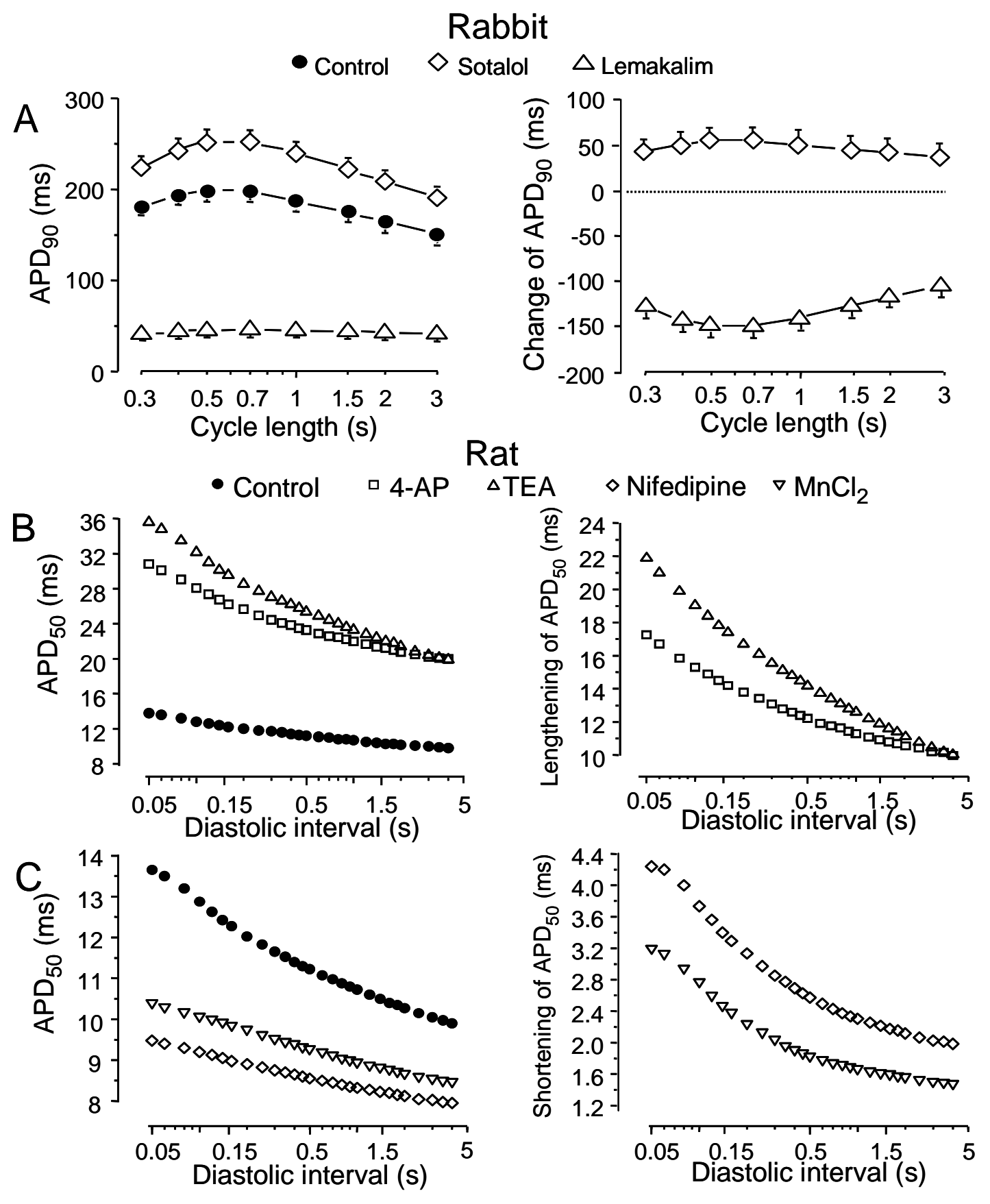

Fig. (5.A) Frequency-dependent effects of $20 \mu \mathrm{M}$ d-sotalol and $15 \mu \mathrm{M}$ lemakalim on APD in rabbit papillary muscle preparations paced at various constant cycle lengths indicated in the abscissa. Note that these drug-induced APD changes failed to follow reverse rate-dependency.

Fig. (5.B,C) Effects of $5 \mathrm{mM}$ 4-aminopyridine, $5 \mathrm{mM}$ tetraethylammonium, $2.5 \mu \mathrm{M}$ nifedipine and $2 \mathrm{mM}$ $\mathrm{MnCl}_{2}$ on the electrical restitution process of rat ventricular myocardium. Here APD was measured as a function of the diastolic interval. Drug effects were more pronounced at the shorter diastolic intervals.

As could be expected from the negative APD - cycle length relationship in rat, all drug-induced APD changes were largely inversely proportional with the diastolic interval (Figs. (5.B) and (5.C)). This result is the opposite of that we have previously seen with canine, guinea pig, and human preparations, where the drug-induced changes were roughly directly related to cycle length. 

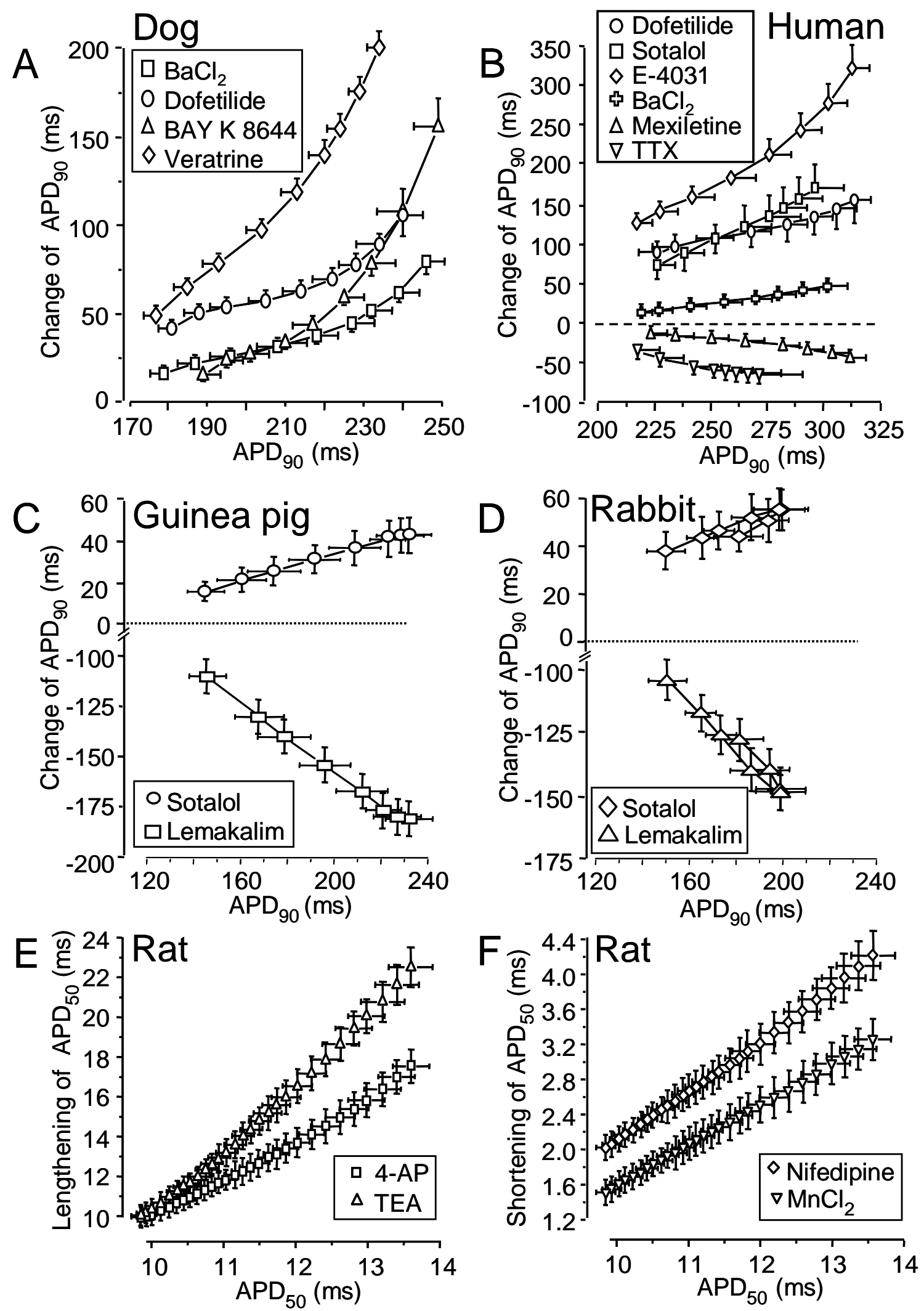

Fig. (6) Drug-induced APD changes plotted as a function of the baseline (pre-drug) value of APD in canine (A), human (B), guinea pig (C), rabbit (D), and rat (E, F) multicellular ventricular preparations. 

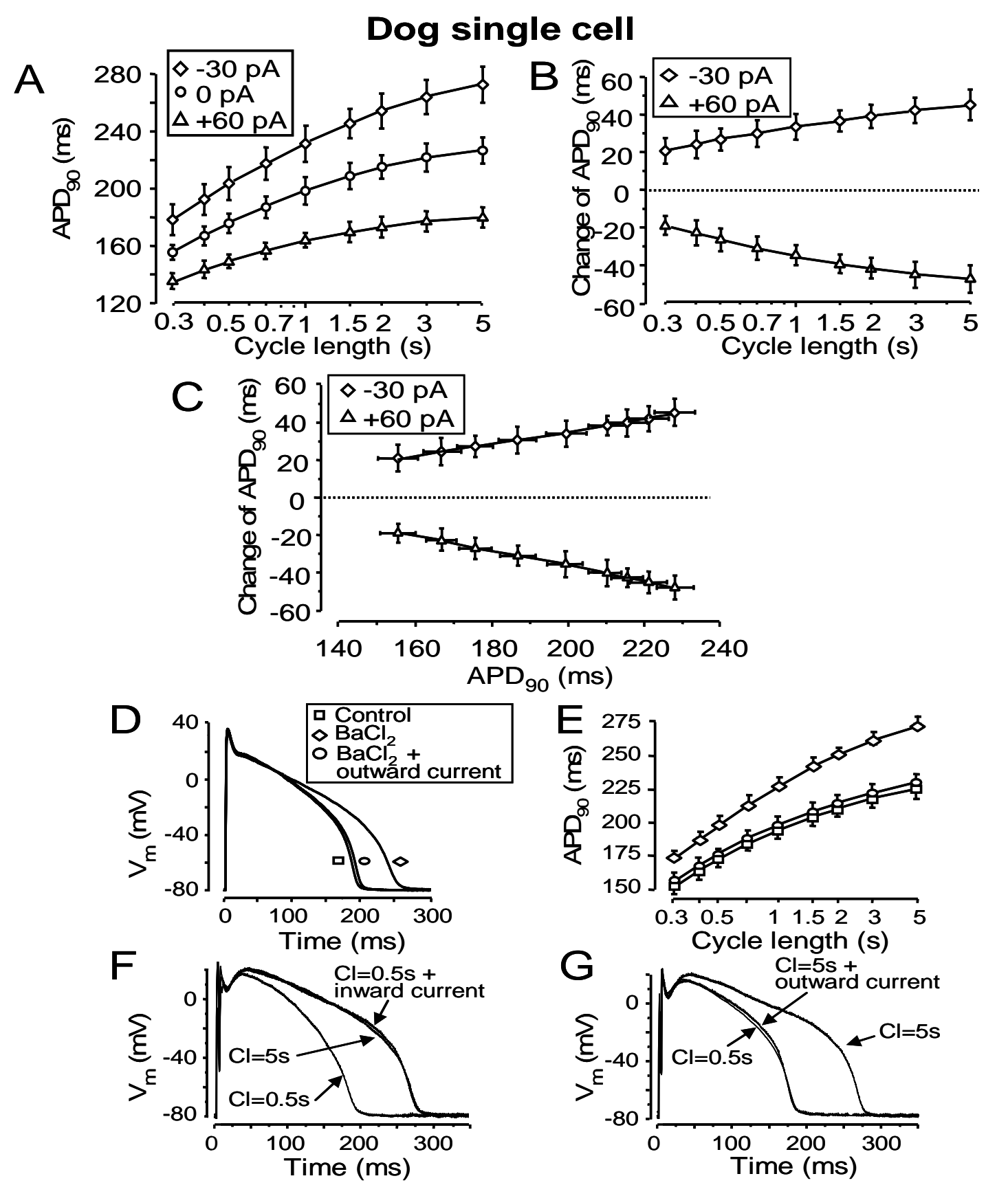

Fig. (7.A-C) Cycle length dependent changes in APD induced by inward (-30 pA) and outward (+60 pA) current pulses, injected throughout the action potential, in single canine ventricular cells. In panel (C) APD changes were plotted against control $(0 \mathrm{pA})$ APD values measured at each cycle length.

Fig. (7.D,E) Combined effects of $\mathrm{BaCl}_{2}$ and outward current injection on frequency-dependent APD changes. Representative superimposed action potentials recorded from a myocyte at $1 \mathrm{~Hz}$ in control, in the presence of $10 \mu \mathrm{M} \mathrm{BaCl}_{2}$, and in case of outward current injection in the presence of $\mathrm{BaCl}_{2}(\mathbf{D})$. The average APD values are plotted as a function of the pacing cycle length in panel (E).

Fig. (7.F,G) Compensation of frequency-dependent APD changes using current injection. The APD shortening caused by increasing the pacing cycle length from 0.5 to $5 \mathrm{~s}$ in panel $(\mathbf{F})$ was compensated by injection of inward current, while the lengthening of APD in response to the opposite frequency change could be compensated by an outward current pulse (G). 
However, when these drug-induced APD changes were studied as a function of the baseline APD in rat, the larger drug effects were observed in cases of the longer baseline action potentials - similarly to results obtained in the other mammalian species. This indicates that dependency of APD on cycle length or diastolic interval and its modulation by drugs are tightly coupled, with cycle length and diastolic interval acting as the modulator of the baseline (pre-drug) APD and the latter directly determining the magnitude of drug-induced changes. This view is reinforced by Fig. (6), in which drug-induced APD changes are demonstrated to be proportional to the baseline (pre-drug) APD value in all the preparations studied so far (dog, human, guinea pig, rabbit, and rat) independently of the pacing cycle length or diastolic interval applied.

\section{REVERSE RATE-DEPENDENCY OF APD CHANGES IS INDEPENDENT OF THE WAY OF INDUCTION}

When studying the effect of an ion channel activator or blocker on action potential configuration, it can be considered as if we have added or removed an inward or outward current to/from the net membrane current flowing during the action potential plateau. This was tested in experiments performed in enzymatically isolated canine ventricular myocytes, impaled with sharp microelectrodes. In the experiments presented in Figs. (7.A-7.C) inward current pulses of -30 pA amplitude were injected into the myocytes in order to lengthen APD. Or alternatively, outward current pulses of $+60 \mathrm{pA}$ amplitude were injected in order to shorten action potentials. All these measurements were performed at various pacing cycle lengths changing gradually from 5 to $0.3 \mathrm{~s}$. As shown in Figs. (7.A-7.C), the effect of a current injection on APD was reversely rate-dependent. Furthermore, the changes in APD induced by the inward and outward current pulses were linearly proportional to baseline APD values measured prior to current injection. Plots generated this way were almost indistinguishable from those obtained with an ion channel agonist or antagonist, indicating that the magnitude of APD modification is exclusively a function of the baseline APD, and independent of the nature of current change (electrical impulse or drug action), the gating kinetics and profiles of the ion current involved, or properties of the drug applied. This point is further demonstrated in Fig. (7.D), showing the effects of reversing the $\mathrm{BaCl}_{2}$-induced prolongation of APD by applying an injection of an outward current pulse. The $\mathrm{BaCl}_{2}$-induced prolongation of APD was completely offset at all cycle lengths by the concomitant injection of the same amount of current (Fig. (7.E)). APD prolongation by $\mathrm{BaCl}_{2}$ is the consequence of $\mathrm{I}_{\mathrm{K} 1}$ blockade. Since, neither $\mathrm{I}_{\mathrm{K} 1}$, nor its inhibition by $\mathrm{BaCl}_{2}$ are significantly rate-dependent, the resulting APD prolongation could be only influenced by the baseline value of APD, which, in turn, was determined by the pacing cycle length. In another series of such experiments, presented in Figs. (7.F) and (7.G), APD modifications induced by abrupt changes in the cycle length could be fully compensated by injections of current pulses having the appropriate amplitudes.

\section{MECHANISM OF REVERSE RATE-DEPENDENCY}

If the magnitude of an APD change of any kind of origin is in fact proportional to the baseline value of APD, it must somehow be related to the change in the net membrane current flowing during the action potential plateau. $\mathrm{I}_{\text {net }}$ was determined at half duration of the action potential from the slope of the middle portion of the plateau using the following simple equation: $I_{n e t}=-C_{m} * d V / d t$, where $C_{m}$ is membrane capacitance and $\mathrm{dV} / \mathrm{dt}$ is the momentary rate of membrane potential change (first time derivative). When $\mathrm{I}_{\text {net }}$ is expressed in $\mathrm{pA} / \mathrm{pF}$, its magnitude equals to the negative slope of the membrane potential change at any point during the action potential. The assumption that APD modulation reflects a change in $\mathrm{I}_{\mathrm{net}}$, independently of the specific current affected, was verified by plotting $\mathrm{I}_{\text {net }}$ against baseline APD under a variety of experimental conditions: at various pacing cycle lengths, before and after applying ion channel blockers or activators, and in the presence or absence of inward or outward current pulses. Four examples to constancy of the $\mathrm{I}_{\text {net }}-$ APD relationship are provided in Fig. (8). In Fig. (8.A) the plotted APD- $\mathrm{I}_{\text {net }}$ data pairs were derived from healthy human papillary muscle preparations exposed to various drugs at various pacing frequencies. Here clearly shown that $\mathrm{I}_{\text {net }}$ was a non-linear function of APD, and the APD- $\mathrm{I}_{\text {net }}$ relationships obtained with different drugs closely overlapped. The plot in Fig. (8.B) demonstrates the APD- $\mathrm{I}_{\text {net }}$ relationship obtained before and after superfusion of canine myocytes with $\mathrm{BaCl}_{2}$, the effect of inward and outward current injections on APD- $\mathrm{I}_{\text {net }}$ relationship is depicted in Fig. (8.C), while the pure cycle length-dependence is presented in Fig. (8.D). Common in all plots that the APD- $\mathrm{I}_{\text {net }}$ relationship 
followed a hyperbolic function, and this shape was preserved independently of the experimental conditions applied.
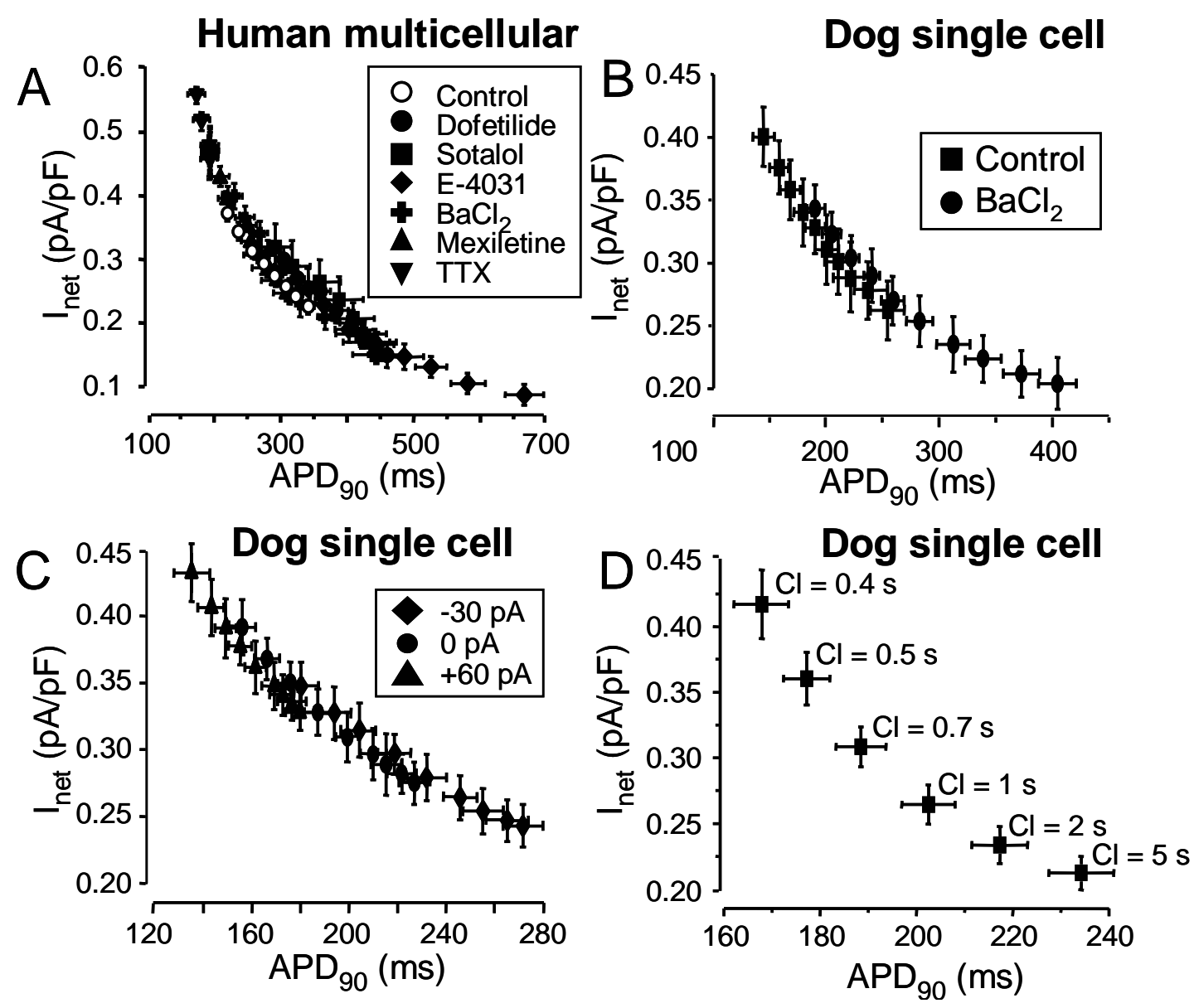

Fig. (8) Reciprocal relationship obtained between action potential duration $\left(\mathrm{APD}_{90}\right)$ and the magnitude of net membrane current $\left(\mathrm{I}_{\text {net }}\right)$ under various experimental conditions.

Based on the result above reverse rate-dependency of drug-effects is a pure consequence of the reverse rate-dependent behavior of APD itself, namely because APD is greater at longer than at shorter cycle lengths in the majority of larger mammals including canine and human ventricular myocardium. In line with this argumentation, drug effects are expected to be positively rate-dependent in a species responding with shortening of APD to reduced pacing rates. Indeed, such changes were observed with sotalol and levkromakalim in rabbit papillary muscles within the range of 0.7-3 s, where APD is decreasing with increasing cycle length, and in rat while studying the effects of $\mathrm{Ca}^{2+}$ and $\mathrm{K}^{+}$channel blockers on the electrical restitution process. Thus the explanation for the reverse rate dependency is quite simple and mechanistic. Since $\mathrm{I}_{\text {net }}$ flowing during the plateau is smaller in the case of a longer than a shorter action potential, a given current added or blocked (either as a current pulse, or due to a pharmacological intervention) is expected to cause a larger relative displacement of $\mathrm{I}_{\text {net }}$, and consequently, a greater change in APD in case of a longer initial action potential. Therefore, the reverse rate-dependent nature of drugaction can be considered as a general intrinsic property of canine and human cardiac cells. 


\section{CONCLUSIONS AND IMPLICATIONS}

The main goal of this study was to show why a drug-induced lengthening or shortening of APD is more pronounced at longer than at shorter cycle length in the majority of mammalian cardiac preparations, independently of the type of the ion current blocked or enhanced. It was also shown that reverse ratedependency seems to be an intrinsic property of the membrane, based on the relation of APD to $\mathrm{I}_{\text {net }}$, rather than the consequence of a specific drug-ion channel interaction $[5,9,35]$, or peculiar kinetics of ion currents [10] - as have been previously proposed. Especially, because lidocaine [23, 36, 37], mexiletine [38], tetrodotoxin [39], and veratrine [40-42] were uniformly shown to display positive rate-dependent interactions with sodium channels (i.e. they exert stronger block or activation of $\mathrm{I}_{\mathrm{Na}}$ at higher frequencies). In spite of this, their action on APD showed clearly reverse rate-dependent characteristics.

Taken together, it appears that reverse rate-dependency - although initially seemed to be a common feature of all cardiac preparations - is restricted only to species showing a positive APD - cycle length relationship. In contrast, since the drug-induced changes in APD well correlated with baseline APD in all of the species studied regardless of the ion current modified or the agent used, one may conclude that reverse ratedependency may simply be a consequence of the inverse relationship existing between $\mathrm{I}_{\text {net }}$ and APD. This confirms the prediction that APD modulation by drugs is more pronounced under conditions when action potentials are $a b$ ovo longer, while the pacing rate being just one of the factors controlling baseline APD. Although the view that the mathematical relationship between APD and $I_{\text {net }}$ may actually cause reverse rate-dependent APD changes was fully confirmed by the present results, several observations indicate that additional mechanisms may also influence the frequency-dependence of APD changes. For instance, if one exclusive mechanism accounted for the reverse rate-dependence, we would expect the relationship between drug-induced APD changes and baseline APD to be identical in all cases. However, such a relationship was almost linear with some drugs, while non-linear with others. This implies that even the dependency of APD modulation on baseline APD may include components that cannot be explained by a single mechanism. Furthermore, the existence of an intrinsic dependency of APD modulation on baseline APD does not rule out the contribution of other genuinely rate-dependent mechanisms, such as drug-ion channel interactions $[5,9,35]$, or rate-dependency of ion current kinetics $[10,43]$ to determine the magnitude of the ratedependent APD change. Indeed, the magnitude of reverse rate-dependency was different among the various drugs tested.

Present results suggest that development of $\mathrm{I}_{\mathrm{Kr}}$ blockers with suitable features may at best reduce reverse rate-dependency of APD modulation, because intrinsic reverse rate-dependency needs to be offset in the first place. Thus, prolongation of APD with direct rate-dependency, although clinically desirable as an antiarrhythmic intervention, may be difficult to attain with any of the selective $\mathrm{I}_{\mathrm{Kr}}$ blocker compounds that are currently used as class 3 antiarrhthmics. A more promising approach might be to combine APD prolongation with interventions suitable to minimize its arrhythmogenic effect at slow heart rates. This can probably be achieved by blocking of plateau inward currents, such as $\mathrm{I}_{\mathrm{Ca}}$ or window $\mathrm{I}_{\mathrm{Na}}$ [44, 45]. This view is supported by the results obtained by either combination of two distinct molecules [46-48], or by applying single drugs having intrinsically combined modes of action [49]. The main conclusion of the present study is that further development of selective $\mathrm{I}_{\mathrm{Kr}}$ blocker drugs as potential class 3 antiarrhytmic agents are not likely to be successful.

\section{LIST OF ABBREVIATIONS}

APD action potential duration

CL cycle length

DI diastolic interval

$\mathrm{I}_{\text {net }} \quad$ net membrane current

\section{ACKNOWLEDGEMENTS}

Financial support for the studies was provided by grants from the Hungarian Research Fund (OTKAK68457, OTKA-K73160, CNK-77855), and the Hungarian Government (TÁMOP-4.2.1/B-09/1/KONV2010-007). The authors thank Mrs Vighné Katalin Horváth for excellent technical assistance. 


\section{REFERENCES}

[1] Hondeghem, L.M.; Snyders DJ. Class III antiarrhythmic agents have a lot of potential but a long way to go. Reduced effectiveness and dangers of reverse use dependence. Circulation, 1990, 81, 686-690.

[2] Horvath, B.; Magyar, J.; Szentandrassy, N.; Birinyi, P.; Nanasi, P.P.; Banyasz, T. Contribution of $\mathrm{I}_{\mathrm{Ks}}$ to ventricular repolarization in canine myocytes. Pflugers Arch., 2006, 452, 698-706.

[3] Nair, L.A.; Grant, A.O. Emerging class III antiarrhythmic agents: mechanism of action and proarrhythmic potential. Cardiovasc. Drugs Ther., 1997, 11, 149-167.

[4] Weirich, J.; Antoni, H. Rate-dependence of antiarrhythmic and proarrhythmic properties of class I and class III antiarrhythmic drugs. Basic Res. Cardiol., 1998, 93 Suppl 1, 125-132.

[5] Jurkiewicz, N.K.; Sanguinetti, M.C. Rate-dependent prolongation of cardiac action potentials by a methanesulfonanilide class III antiarrhythmic agent. Specific block of rapidly activating delayed rectifier $\mathrm{K}^{+}$current by dofetilide. Circ. Res., 1993, 72, 75-83.

[6] Varró, A.; Baláti, B.; Iost, N.; Takács, J.; Virág, L.; Lathrop, D.A.; Lengyel, Cs.; Tálosi, L.; Papp, J.Gy. The role of the delayed rectifier component $\mathrm{I}_{\mathrm{Ks}}$ in dog ventricular muscle and Purkinje fibre repolarization. J. Physiol. (London), 2000, 523, 67-81.

[7] Starmer, C.F.; Grant, A.O. Phasic ion channel blockade. A kinetic model and parameter estimation procedure. Mol. Pharmacol., 1985, 28, 348-356.

[8] Hondeghem, L.M.; Katzung, B.G. Time- and voltage-dependent interactions of antiarrhythmic drugs with cardiac sodium channels. Biochim. Biophys. Acta, 1977, 472, 373-398.

[9] Yang, T.; Roden, D.M. Extracellular potassium modulation of drug block of $\mathrm{I}_{\mathrm{Kr}}$. Implications for torsade de pointes and reverse use-dependence. Circulation, 1996, 93, 407-411.

[10] Rocchetti, M.; Besana, A.; Gurrola, G.B.; Possani, L.D.; Zaza, A. Rate dependency of delayed rectifier currents during the guinea-pig ventricular action potential. J. Physiol. (London), 2001, 534, 721-732.

[11] Varro, A.; Virag, L.; Acsai, K.; Hala, O.; Zaza, A.; Bitay, M.; Bogáts, G.; Papp, J.G.; Varró, A. Self augmentation of the repolarization lengthening is related to the shape of the action potential: the role of the intrinsic properties of $\mathrm{I}_{\mathrm{Kr}}$ and $\mathrm{I}_{\mathrm{K} 1}$ and its implication to reverse rate dependency. Br. J. Pharmacol., 2009, 156, 1076-1084.

[12] Bányász, T.; Horváth, B.; Virág, L.; Bárándi, L.; Szentandrássy, N.; Harmati, G.; Magyar, J.; Marangoni, S.; Zaza, A.; Varró, A.; Nánási P.P. Reverse rate dependency is an intrinsic property of canine cardiac preparations. Cardiovasc. Res., 2009, 84, 237-244.

[13] Zaza, A. Control of cardiac action potential: The role of repolarization dynamics. J. Mol. Cell. Cardiol., 2010, 48, 106-111.

[14] Bárándi, L.; Virág, L.; Jost, N.; Horváth, Z.; Koncz, I.; Papp, R.; Harmati, G.; Horváth, B.; Szentandrássy, N.; Bányász, T.; Magyar, J.; Zaza, A.; Varró, A.; Nánási, P.P. Reverse rate-dependent changes are determined by baseline action potential duration in mammalian and human ventricular preparations. Basic Res. Cardiol., 2010, 105, 315-323.

[15] Bárándi, L.; Harmati, G.; Horváth, B.; Szentandrássy, N.; Bányász, T.; Magyar, J.; Varró, A.; Nánási, P.P. Drug-induced changes in action potential duration are proportional to action potential duration in rat ventricular myocardium. Gen. Physiol. Biophys., 2010, 29, 308-312. 
[16] Bányász, T.; Magyar, J.; Szigligeti, P.; Pankucsi, C.; Varró, A.; Nánási, P.P. Frequency-dependent characteristics of human cardiac muscle. Exp. Clin. Cardiol., 1997, 2, 205-209.

[17] Baláti, B.; Varró, A.; Papp, J.G. Comparison of the cellular electrophysiological characteristics of canine left ventricular epicardium, M cells, endocardium and Purkinje fibres. Acta Physiol. Scand., 1998, 164, 181-190.

[18] Szabó, G.; Szentandrássy, N.; Bíro, T.; Tóth, B.I.; Czifra, G.; Magyar, J.; Bányász, T.; Varró, A.; Kovács, L.; Nánási, P.P. Asymmetrical distribution of ion channels in canine and human left-ventricular wall: epicardium versus midmyocardium. Pflugers Arch., 2005, 450, 307-316.

[19] Szentadrássy, N.; Bányász, T.; Bíro, T.; Szabó, G.; Tóth, B.I.; Magyar, J.; Lázár, J.; Varró, A.; Kovács, L.; Nánási, P.P. Apico-basal inhomogeneity in distribution of ion channels in canine and human ventricular myocardium. Cardiovasc. Res., 2005, 65, 851-860.

[20] Shieh, R.-C.; Chang, J.-C.; Arreola, J. Interaction of $\mathrm{Ba}^{2+}$ with the pores of the cloned inward rectifier $\mathrm{K}^{+}$channels Kir2.1 expressed in Xenopus oocytes. Biophys. J., 1998, 75, 2313-2322.

[21] Markwardt, F.; Nilius, B. Modulation of calcium channel currents in guinea-pig single ventricular heart cells by the dihydropyridine Bay K 8644. J. Physiol. (London), 1988, 399, 559-575.

[22] Zong, X.G.; Dugas, M.; Honerjager, P. Relation between veratridine reaction dynamics and macroscopic Na current in single cardiac cells. J. Gen. Physiol., 1992, 99, 683-697.

[23] Grant, A.O.; Dietz, M.A.; Gilliam, F.R.; Starmer, C.F. Blockade of cardiac sodium channels by lidocaine. Circ. Res., 1989, 65, 1247-1262.

[24] Imanishi, S.; Arita, M.; Kiyosue, T.; Aomine, M. Effects of SG-75 (nicorandil) on electrical activity of canine cardiac Purkinje fibers: possible increase of potassium conductance. J. Pharmacol. Exp. Ther., 1983, 225, 198-205.

[25] Varró, A.; Lathrop, D.A.; Hester, S.B.; Nánási, P.P.; Papp, J.GY. Ionic currents and action potentials in rabbit, rat and guinea pig ventricular myocytes. Basic Res. Cardiol., 1993, 88, 93-102.

[26] Berger, F.; Borchard, U.; Hafner, D. Effects of (+)- and ( \pm )-sotalol on repolarizing outward currents and pacemaker current in sheep cardiac Purkinje fibres. Naunyn-Schmiedeberg's Arch. Pharmacol., 1989, 340, 696-704.

[27] Szigligeti, P.; Pankucsi, C.; Bányász, T.; Varró, A.; Nánási, P.P. (1996): Action potential duration and force-frequency relationship in isolated rabbit, guinea pig and rat cardiac muscle. J. Comp. Physiol. B, 1996, 166, 150-155.

[28] Josephson, I.R.; Sanches-Chapula, J.; Brown, A.M. Early outward current in rat single ventricular cells. Circ. Res., 1984, 54, 157-162.

[29] Apkon, M.; Nerbonne, J.M. Characterization of two distinct depolarization-activated $\mathrm{K}^{+}$currents in isolated adult rat ventricular myocytes. J. Gen. Physiol., 1991, 97, 973-1011.

[30] Yuan, W.; Ginsburg, K.S.; Bers, D.M. Comparison of sarcolemmal calcium channel current in rabbit and rat ventricular myocytes. J. Physiol. (London), 1996, 493, 733-746.

[31] Carmeliet, E. Repolarization and frequency in cardiac cells. J. Physiol. (Paris), 1977, 73, 903-923.

[32] Shigematsu, S.; Kiyosue, T.; Sato, T.; Arita M. Rate-dependent prolongation of action potential duration in isolated rat ventricular myocytes. Basic Res. Cardiol., 1997, 92, 123-128. 
[33] Mitchell, M.R.; Powell, T.; Terrar, D.A.; Twist, V.W. Strontium, nifedipine and 4-aminopyridine modify the time course of the action potential in cells from rat ventricular muscle. Br. J. Pharmacol., 1984, 81, 551-556.

[34] Elharrar, V.; Atarashi, H.; Surawicz, B. Cycle length-dependent action potential duration in canine cardiac Purkinje fibers. Am. J. Physiol., 1984, 247, H936-H945.

[35] Hondeghem, L.M.; Katzung, B.G. Antiarrhythmic agents: the modulated receptor mechanism of action of sodium and calcium channel-blocking drugs. Annual Rev. Pharmacol. Toxicol., 1984, 24, 387-423.

[36] Campbell, T.J. Kinetics of onset of rate-dependent effects of Class I antiarrhythmic drugs are important in determining their effects on refractoriness in guinea-pig ventricle, and provide a theoretical basis for their subclassification. Cardiovasc. Res., 1983, 17, 344-352.

[37] Grant, A.O.; Dietz, M.A.; Gilliam, F.R.; Starmer, C.F. Blockade of cardiac sodium channels by lidocaine: single-channel analysis. Circ. Res., 1989, 65, 1247-1262.

[38] Ono, M.; Sunami, A.; Hiraoka, M. Interaction between external $\mathrm{Na}^{+}$and mexiletine on $\mathrm{Na}^{+}$channel in guinea-pig ventricular myocytes. Pflügers Arch., 1995, 431, 101-109.

[39] Varró, A.; Nakaya, Y.; Elharrar, V.; Surawicz, B. Frequency-dependent and independent effects of tetrodotoxin on $\mathrm{V}_{\max }$ in cardiac fibers. Acta Physiol. Hung., 1989, 73, 47-52.

[40] Barnes, S.; Hille, B. Veratridine modifies open sodium channels. J. Gen. Physiol., 1988, 91, 421-443.

[41] Leibowitz, M.D.; Sutro, J.B.; Hille, B. Voltage-dependent gating of veratridine-modified Na channels. J. Gen. Physiol., 1986, 87, 25-46.

[42] Zong, X.G.; Dugas, M.; Honerjager, P. Relation between veratridine reaction dynamics and macroscopic Na current in single cardiac cells. J. Gen. Physiol., 1992, 99, 683-697.

[43] Virág, L.; Acsai, K.; Hála, O.; Zaza, A.; Bitay, M.; Bogáts, G.; Papp, J.G.; Varró, A. Self augmentation of the lengthening of repolarization is related to the shape of the cardiac action potential: implication for reverse rate dependency. Br. J. Pharmacol., 2009, 156, 1076-1084.

[44] Wu, L.; Shryock, J.C.; Song, Y.; Li, Y.; Antzelevitch, C.; Belardinelli, L. Antiarrhythmic effects of ranolazine in a guinea pig in vitro model of long-QT syndrome. J. Pharmacol. Exp. Ther., 2004, 310, 599605.

[45] Zaza, A.; Belardinelli, L.; Shryock, J.C. Pathophysiology and pharmacology of the cardiac "late sodium current". Pharmacol. Ther., 2008, 119, 326-339.

[46] Bril, A.; Forest, M.C.; Cheval, B.; Faivre, J.F. Combined potassium and calcium channel antagonistic activities as a basis for neutral frequency dependent increase in action potential duration: comparison between BRL-32872 and azimilide. Cardiovasc. Res., 1998, 37, 130-140.

[47] Lathrop, D.A.; Varro, A. The combined electrophysiological effects of lignocaine and sotalol in canine isolated cardiac Purkinje fibres are rate-dependent. Br. J. Pharmacol., 1990, 99, 124-130.

[48] Varro, A.; Lathrop, D.A. Sotalol and mexiletine: combination of rate-dependent electrophysiological effects. J. Cardiovasc. Pharmacol., 1990, 16, 557-567.

[49] Matyus, P.; Varga, I.; Rettegi, T.; Simay, A.; Kallay, N.; Karolyhazy, L.; Kocsis, A.; Varró, A.; Pénzes, I.; Papp, J.G. Novel antiarrhythmic compounds with combined class IB and class III mode of action. Curr. Med. Chem., 2004, 11, 61-69. 